\title{
Electrochemical Corrosion Damage Detection Test of Steel Pipe Based on Piezoelectric Ceramics
}

Bin $\mathrm{Hu}^{1}$, Yanhua She ${ }^{1 *}$

${ }^{1}$ School of Urban Construction, Yangtze University, Jingzhou 434023, China

DOI: $10.36347 /$ sjet.2021.v09i03.001

| Received: 22.02.2021 | Accepted: 03.03.2021 | Published: 06.03.2021

*Corresponding author: Yanhua She

Abstract

Original Research Article

In this paper, the steel pipe was corroded by electric chemistry. The piezoelectric ceramic sensor was placed on the normal surface and the corrosion surface respectively. The active induction method of the piezoelectric ceramic sensor was used to detect the steel pipe with different corrosion degrees. The results show that the greater the degree of corrosion of the steel pipe, the smaller the signal voltage value received by the piezoelectric ceramic sensor, and the greater the damage index. The active induction method can be used to detect the damage change of the corrosion of the steel pipe through the piezoelectric ceramic sensor.

Keywords: Steel pipe, Electrochemical corrosion, Piezoelectric ceramic sensors, Damage detection.

Copyright $(\mathcal{C} 2021$ The Author(s): This is an open-access article distributed under the terms of the Creative Commons Attribution 4.0 International License (CC BY-NC 4.0) which permits unrestricted use, distribution, and reproduction in any medium for non-commercial use provided the original author and source are credited.

\section{INTRODUCTION}

Pipeline engineering as a project covering many fields, lots of factors affect the normal operation of its structure. Among them, pipeline corrosion will greatly reduce the strength of the pipeline itself and the bearing capacity coefficient [1-3], and even cause perforation, which will lead to leakage and damage of the pipeline, bring great impact on people's life, and also be the main factor of some secondary disasters [4]. The structural damage detection and health monitoring of buried pipeline after corrosion is one of the important research directions $[5,6]$, and the active induction method for structural damage detection by using piezoelectric ceramic sensor (PZT) is one of the more novel methods [7]. Compared with other detection methods, this method has better energy collection ability, high sensitivity and low price. In recent years, it is widely used in aerospace engineering, mechanical engineering and civil engineering $[8,9]$.

In this paper, the steel pipe is immersed in 5\% $\mathrm{NaCl}$ solution for electrochemical corrosion test, which is carried out for 6 days and 12 hours every day. And the real-time detection based on PZT sensor active induction method is carried out every 6 hours. The maximum voltage value of each detection is recorded and analyzed. Finally, combined with energy analysis based on wavelet packet, the signal graph and pipeline damage index are obtained.

\section{Test Principle \\ Principle of electrochemical corrosion}

The essence of electrochemical corrosion is that iron products are electrolyzed in electrolyte solution, resulting in electrochemical reaction and corrosion current, which meets the requirements of electrochemical kinetics [10]. This test belongs to oxygen absorption corrosion, and its chemical principle is shown in Formula 1.

$$
\begin{gathered}
\text { Anode, } \mathrm{Fe}-2 e \rightarrow \mathrm{Fe}^{2+} \\
\text { Cathode, } \mathrm{O}_{2}+2 \mathrm{H}_{2} \mathrm{O}+4 \mathrm{e} \rightarrow 4 \mathrm{OH}^{-} \\
\text {Chemical reaction formula, } \quad \begin{array}{r}
4 \mathrm{Fe}+3 \mathrm{O}_{2}+2 \mathrm{H}_{2} \mathrm{O} \rightarrow 4 \mathrm{Fe}(\mathrm{OH})_{2} \\
2 \mathrm{Fe}(\mathrm{OH})_{2} \rightarrow \mathrm{Fe}_{2} \mathrm{O}_{3}+\mathrm{H}_{2} \mathrm{O}
\end{array}
\end{gathered}
$$

\section{Piezoelectric ceramic active induction method}

In this experiment, the active detection method of PZT sensor is used to detect the damage changes of steel pipe at different stages of corrosion. As shown in Fig-1, stress wave is generated by the pzt2 sensor, which is received by the pzt1 sensor and the pzt3 sensor. The performance parameters of PZT sensors are shown in Table-1. When the steel pipe is corroded, the stress wave will be partially reflected due to the corrosion of the steel pipe, which leads to a certain signal reduction of pztl sensor. If the corrosion phenomenon is more serious, the signal received by pzt1 sensor will be weaker. Finally, the damage energy of steel pipe after electrochemical corrosion is converted into damage index by using energy method based on wavelet packet. 


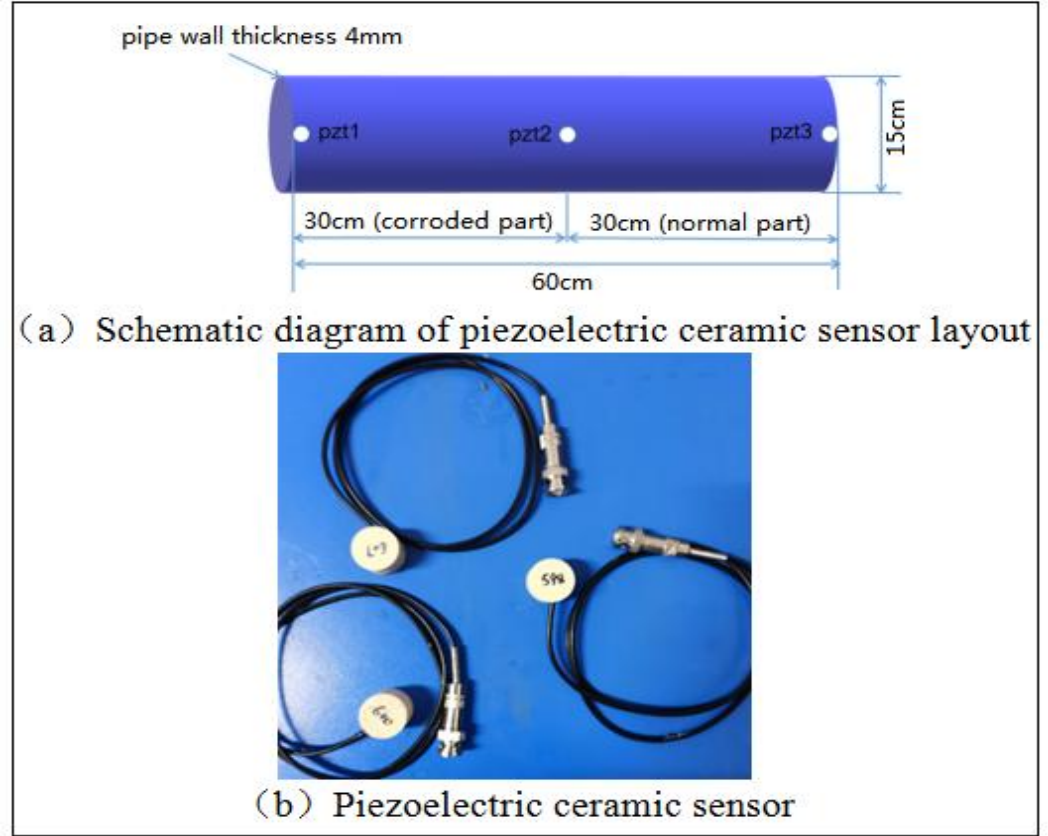

Fig-1: Active induction method

Table-1: Piezoelectric ceramic sensor the performance parameters

\begin{tabular}{|l|l|l|l|l|l|l|l|}
\hline category & $\begin{array}{l}\text { density } \\
\left(\mathbf{k g} / \mathbf{m}^{\mathbf{3}}\right)\end{array}$ & $\begin{array}{l}\text { curie } \\
\text { temperature } \\
\left({ }^{\circ} \mathrm{C}\right)\end{array}$ & $\begin{array}{l}\text { mechanical } \\
\text { quality } \\
\text { factors }\left(\mathbf{Q}_{\mathbf{m}}\right)\end{array}$ & $\begin{array}{l}\text { poisson's } \\
\text { ratio }\end{array}$ & $\begin{array}{l}\text { relative } \\
\text { permittivity } \\
\left(\boldsymbol{\varepsilon}_{\mathbf{r 3 3}} / \boldsymbol{\varepsilon}_{\mathbf{r} 0}\right)\end{array}$ & $\begin{array}{l}\text { dielectric } \\
\text { loss } \\
(\tan \delta)\end{array}$ & $\begin{array}{l}\text { electromechanical } \\
\text { coupling coefficient } \\
\mathbf{K}_{\mathbf{3 3}}\end{array}$ \\
\hline value & 7500 & 350 & 80 & 0.3 & 1500 & 0.025 & 0.60 \\
\hline
\end{tabular}

\section{Energy analysis method based on wavelet packet}

The energy analysis method of wavelet packet can transform the received time-frequency signal into the required energy data through calculation, and then put forward the concept of damage index, which can be used to judge the degree of damage. In this study, energy analysis based on wavelet packet is used to calculate the energy of signals received by different damage degrees of steel pipe in corrosion stage. The energy of monitoring signal of steel pipe in normal state before corrosion is set as the initial energy $E_{h}$, and the energy of steel pipe in a certain detection period is $E_{i}$. Then the structural damage index $\mathrm{D}_{\mathrm{i}}$ can be obtained by conversion as follows

$D_{i}=1-\frac{E_{i}}{E_{h}}=\left(1-\frac{\sum_{n=0}^{+\infty}\left|x_{i}(n)\right|^{2}}{\sum_{n=0}^{+\infty}\left|x_{h}(n)\right|^{2}}\right) \times 100 \%$

Where $x_{i}(n)$ and $x_{h}(n)$ are the energy values of discrete signals collected by sensors under normal state and damage state respectively. It can be seen from Formula 2 that when the value of $\mathrm{D}_{\mathrm{i}}$ is within 0 to 1 , the damage degree of the structure is inversely proportional to $\mathrm{D}_{\mathrm{i}}$; similarly, when $\mathrm{D}_{\mathrm{i}}=1$, the structure is completely invalid; when $\mathrm{D}_{\mathrm{i}}=0$, the structure is in a healthy state. Therefore, the damage degree of the structure can be judged by the size of $D_{i}[11]$.

\section{Test Overview}

\section{Test Equipment}

The test equipment includes PS 305 DC stable power supply, signal transmitter, data acquisition instrument (NIUSB-6361), computer and Q235 steel pipe. As shown in Fig-2, the DC stabilized power supply is set to $1 \mathrm{~A}$ and remains constant. As shown in Fig-3, a series of instruments such as data acquisition instrument and signal transmitter are needed for damage detection. In this test, the sampling frequency of the data acquisition instrument is always set to $2 \mathrm{MS} / \mathrm{s}$, while the starting frequency, ending frequency, voltage value and period are $10 \mathrm{~Hz}, 100 \mathrm{kHz}, 10 \mathrm{~V}$ and $1 \mathrm{~s}$ respectively. In order to avoid the influence of many external factors when the piezoelectric ceramic sensor is tested again, the test is carried out in a quiet and closed laboratory.

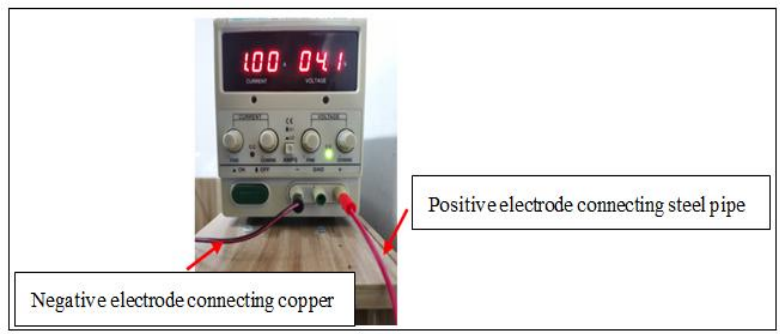

Fig-2: PS 305 DC stable power supply 


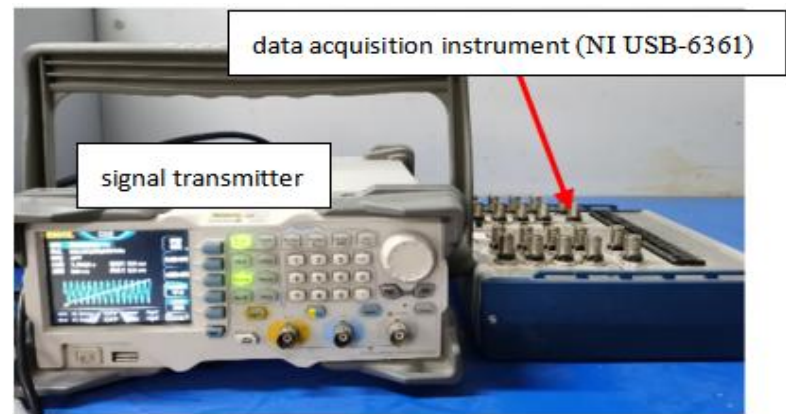

Fig-3: Piezoelectric ceramic damage detection equipment

\section{Experimental Design}

As shown in Fig-4, $5 \% \mathrm{NaCl}$ solution is injected into the PVC anticorrosive plastic container with a height of $30 \mathrm{~cm}$. The Q235 steel pipe with a diameter of $15 \mathrm{~cm}$ and a height of $60 \mathrm{~cm}$ is put into the solution vertically, and then three sensors named pzt1, pzt 2 and pzt 3 are arranged at $0 \mathrm{~cm}, 30 \mathrm{~cm}$ and $60 \mathrm{~cm}$ respectively, and the coupling agent of silicone grease is used to make them adhere to the steel pipe. The positive pole of the stable power supply is connected with the steel pipe, and the negative pole is connected with a copper sheet, which is put into the solution and close to the PZT sensor side. The electrochemical corrosion test lasts for six days and is carried out for 12 hours every day. PZT active induction test is carried out every 6 hours.

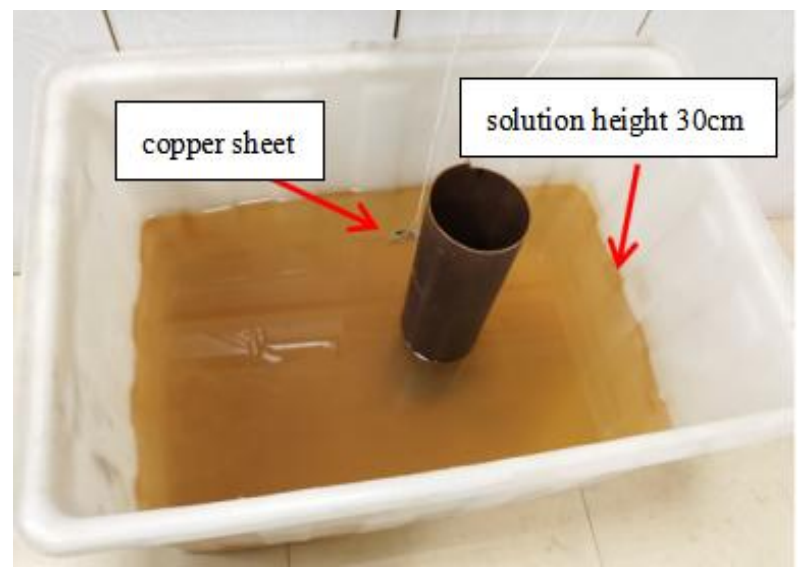

Fig-4: Diagram of electrochemical corrosion test apparatus

\section{Analysis of test results \\ Corrosion results of steel pipe}

As shown in Fig-5, the corrosion phenomenon of steel pipe in the process of constant current electrochemical corrosion becomes more and more significant with the passage of time, and the corrosion near the copper sheet is the most obvious. When the local corrosion time is $0-12 \mathrm{~h}$, the corrosion degree of the steel pipe is mild, and uniform fine particles appear on the surface of the steel pipe. After $12 \mathrm{~h}-36 \mathrm{~h}$, the corrosion degree of steel pipe is moderate, and the surface of steel pipe appears reddish brown rust. The results show that the corrosion degree of the steel pipe is serious at $36 \mathrm{~h}-48 \mathrm{~h}$, and there is dark brown flake rust layer on its surface. During $48 \mathrm{~h}-72 \mathrm{~h}$, the corrosion degree of the steel pipe is very serious. There are many copper green rust blocks on the surface of the steel pipe, and the surface damage is very serious. If the test is continued, it is very likely that the steel pipe will be damaged by perforation.

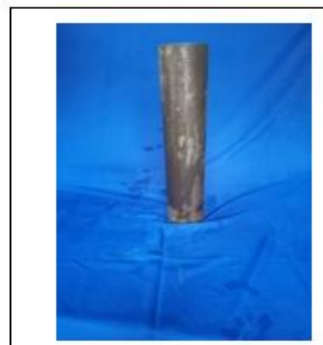

(a) corrosion for $6 \mathrm{~h}$

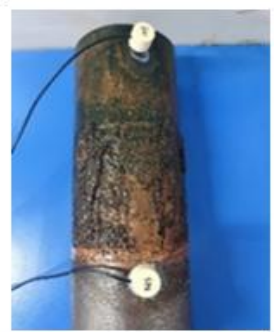

(c) corrosion for $48 \mathrm{~h}$

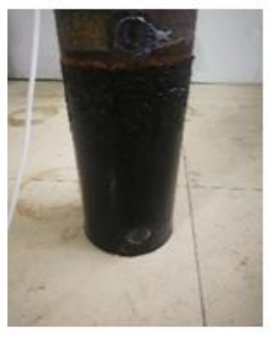

(b) corrosion for $24 \mathrm{~h}$

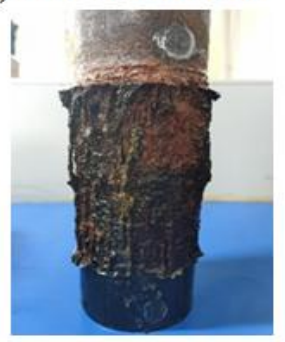

(d) corrosion for $72 \mathrm{~h}$
Fig-5: Steel tube specimen after different corrosion time

\section{Analysis of damage detection results}

As shown in Fig.6, through the data measured by the data acquisition instrument, the change trend of the maximum voltage value in different time periods in the process of steel tube electrochemical corrosion is obtained. The maximum voltage of the normal surface does not change, but the corrosion surface is obvious. It can be observed that the corrosion damage to the steel pipe itself is extremely significant. The maximum voltage decreases with the increase of corrosion time, and the maximum voltage of the corrosion surface is only $1 / 7$ of the initial maximum voltage.

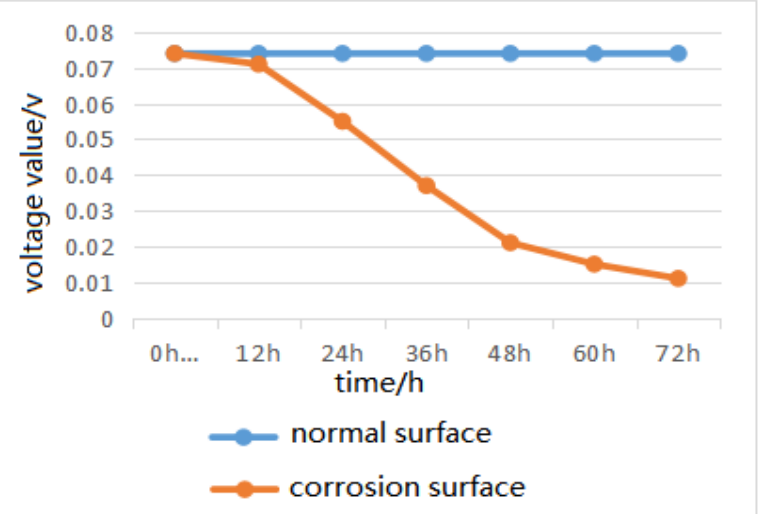

Fig-6: Trend chart of maximum voltage variation

As shown in Fig-7, the diagram is the time domain signal diagram of the corrosion surface. The stress wave is generated by the pzt 2 sensor and finally received by the pzt1 sensor. By using the energy 
analysis method of wavelet packet, the energy change trend of stress wave can be clearly observed. The period of each curve of sensor signal is $1 \mathrm{~s}$. The corrosion damage trend of steel pipe can be judged by observing the maximum voltage.

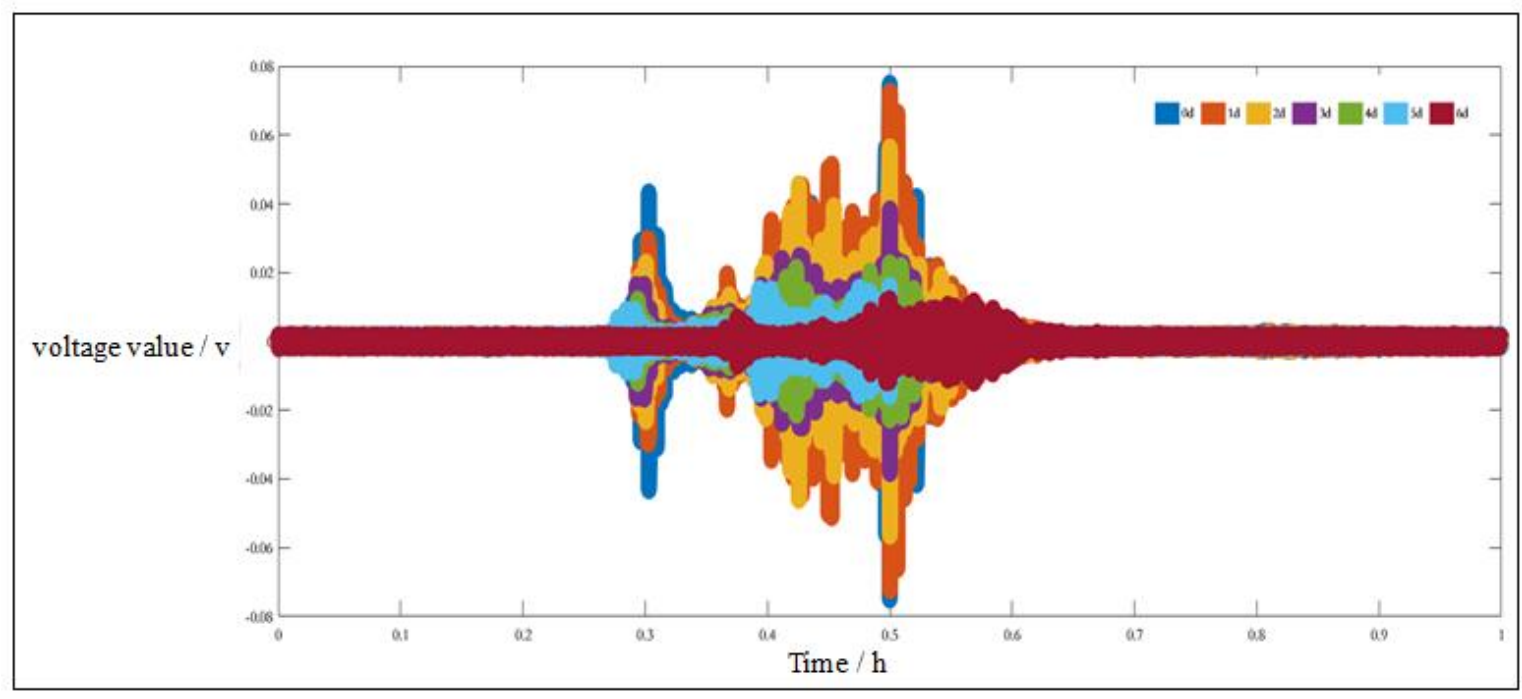

Fig-7: Time domain signal diagram of corrosion surface

By using the energy analysis method of wavelet packet, the energy change trend of stress wave can be clearly observed. It can be transformed into damage index by Formula 2. As shown in Fig-8, with the passage of corrosion time, the damage degree of the corroded surface of the steel pipe gradually increases, and the damage index also increases. From $12 \mathrm{~h}$ mild corrosion to $72 \mathrm{~h}$ very severe corrosion, the damage index increases from 0.3 to 0.91 .

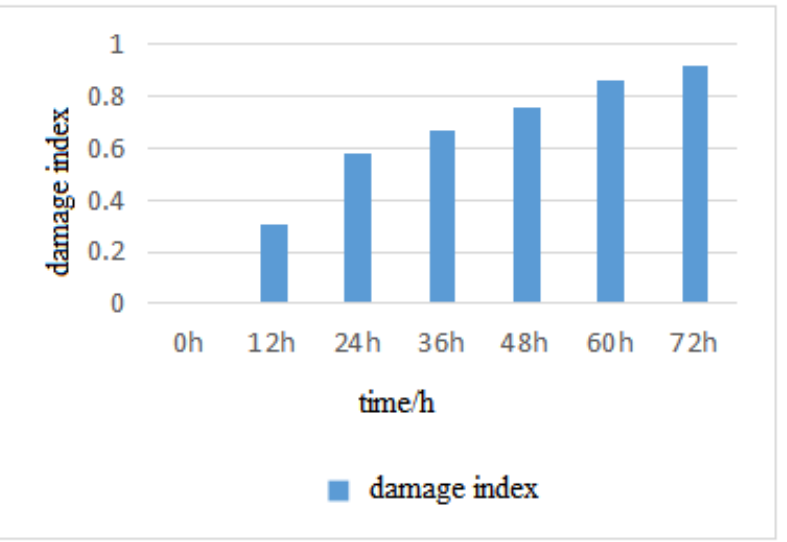

Fig-8: Corrosive surface damage index variation diagram

The experimental results show that the damage index converted by energy analysis of wavelet packet can be used to reflect the damage trend of steel pipe corrosion, and the damage change can also be detected by using piezoelectric ceramic sensor through active induction method. This test further proves that PZT sensor can be applied to the corrosion damage detection of steel pipe, and can also judge the current health state of pipeline according to the measured data.

\section{CONCLUSION}

In this paper, the electrochemical corrosion of the steel pipe is carried out, and the piezoelectric ceramic sensor is pasted on the steel pipe by using the active induction method, so as to detect the damage changes of the steel pipe in the corrosion process. The results show that: when the corrosion time of steel pipe is longer and the corrosion degree is deeper, the amplitude of wave signal received by PZT sensor gradually decreases, and the maximum voltage value measured gradually decreases; according to the timefrequency signal graph and the damage index obtained by energy analysis based on wavelet packet, the steel pipe corrosion can be detected in real time by using the active induction method of piezoelectric ceramic sensor. The corrosion damage detection method of steel pipe based on piezoelectric ceramics proposed in this paper has good feasibility, and has certain reference significance for practical engineering.

\section{ACKNOWLEDGEMENTS}

This work is financially supported by National Natural Science Foundation of China (NSFC, 51408057) \& Youth Talent Project of Yangtze University (2015cqr06).

\section{REFERENCES}

1. Li, X., \& Chen, C. F. (2020). Research progress on AC corrosion of buried oil and gas pipelines. Material Protection, 53(9):114-120.

2. Chen, M. C., Fang, W., \& Huang, H. (2020). Study on static behavior of concrete filled steel tubular members corroded by simulated acid rain. Engineering Mechanics, 37(2), 34-43.

3. Zhen, Z., Li, Y. L., \& Jin, H. (2018). Microstructure and corrosion resistance of pipe pile 
steel for hydraulic engineering. Corrosion and Protection, 39(7):501-510.

4. Yang, H. (2015). Research on acoustic emission monitoring technology for corrosion damage of pipeline structure. Dalian University of Technology.

5. Wang, D., Song, H., \& Zhu, H. (2013). Numerical and experimental studies on damage detection of a concrete beam based on PZT admittances and correlation coefficient. Construction and Building Materials, 49, 564-574.

6. Li, X., Cui, H., Zhang, B., \& Yuan, C. (2017, October). Experimental study of a structural health monitoring method based on piezoelectric element array. In 2017 IEEE 3rd Information Technology and Mechatronics Engineering Conference (ITOEC) (pp. 27-31). IEEE.

7. Kong, Q., Fan, S., Bai, X., Mo, Y. L., \& Song, G. (2017). A novel embeddable spherical smart aggregate for structural health monitoring: Part I. Fabrication and electrical characterization. Smart Materials and Structures, 26(9), 095050.

8. Pillatsch, P., Xiao, B. L., Shashoua, N., Gramling, H. M., Yeatman, E. M., \& Wright, P. K. (2017). Degradation of bimorph piezoelectric bending beams in energy harvesting applications. Smart Materials and Structures, 26(3), 035046.

9. Xu, L. J., \& Wang, Q. P. (2013). Review on the application of guided wave technology in pipeline damage detection. Yellow River, (3):124-126.

10. Jia, S. C., Gao, J. Q., \& Guo, H. (2020). Study on corrosion of cast iron pipe caused by reclaimed water quality factors. Chinese Journal of Corrosion and Protection, 40(6), 569-576.

11. Liu, X. Y., Rao, Y. L., \& Zhang, J. C. (2020). Damage monitoring of wood under axial compression based on piezoelectric sensor. Piezoelectric and Acoustooptic, 42(5), 681-685. 